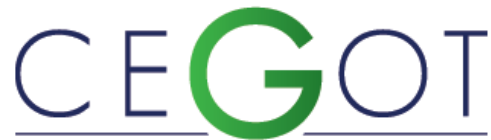

Centro de Estudos de Geografia e Ordenamento do Território
Geografia e Ordenamento do Território, Revista Eletrónica Centro de Estudos de Geografia e Ordenamento do Território http://cegot.org BATISTA, ELICARDO

Universidade Estadual Paulista Júlio de Mesquita Filho, Faculdade de Ciências e Tecnologia de Presidente Prudente, Departamento de Geografia

5 Rua Roberto Simonsen, 305. Centro Educacional, 19060-900 - Presidente Prudente, SP - Brasil - Caixa-postal: 266 elicardoheber@yahoo.com.br

\title{
Pobreza rural e políticas sociais nas sociedades contemporâneas: uma experiência no Brasil
}

Rural poverty and social policies in contemporary societies: an experience in Brazil

Referência: Batista, Elicardo (2018). Pobreza rural e políticas sociais nas sociedades contemporâneas: uma experiência no Brasil. Revista de Geografia e Ordenamento do Território (GOT), n. ${ }^{\circ} 14$ (setembro). Centro de Estudos de Geografia e Ordenamento do Território, p. 109-133, dx.doi.org/10.17127/got/2018.14.004

\section{RESUMO}

Este artigo apresentará uma discussão sobre o processo de ampliação de políticas sociais em regiões carentes e os impactos das referidas politicas nas condições de vida de famílias pobres residentes em áreas rurais de Minas Gerais, Brasil. Baseada sobretudo em metodologias qualitativas na produção de evidências, principalmente entrevista abertas, de forma sintética, o texto centrará em experiência locais no Brasil, sobretudo, no Vale do Jequitinhonha (MG). A referida mesorregião mineira é bastante emblemática por se apresentar no cenário brasileiro como um "bolsão de miséria", definida a partir dos indicadores de alta incidência de pobreza (econômica). No geral, entre as famílias localizadas na base da estrutura social, sobretudo em relação a renda monetária, a universalização e o crescimento exponencial (ainda que extremamente insuficiente) das políticas sociais, têm representado elementos fundamentais na melhoria das condições de vida dos mais pobres.

Palavras-Chave: Pobreza, Pobreza Rural, Estado, Políticas Sociais, Vale do Jequitinhonha.

\section{ABSTRACT}

his article will present a discussion about the process of expanding social policies in needy regions and the impacts of these on living conditions of poor families living in rural areas of Minas Gerais, Brazil. Based mainly on qualitative methodologies for production of evidence, mainly open interview, in a synthetic way, the text will focus on local experience in Brazil, especially in Jequitinhonha Valley (MG). This mining mesoregion is quite emblematic, once it presents itself in Brazilian scenario as a "pocket of misery", defined by high incidence of (economic) poverty indicators. In general, among the families located at the base of the social structure, especially concerning monetary income, the universalization and the exponential growth (although extremely insufficient) of social policies, have been exemples of fundamental improving elements on living conditions for the poorest. 
Keywords: Poverty, Rural Poverty, State, Social Policies, Jequitinhonha Valley.

\section{Introdução}

A temática da pobreza tem ocupado um lugar de destaque nas agendas públicas nacionais e internacionais; e diferentes governos, entre eles, o brasileiro, têm ampliado os programas e as políticas (sobretudo as sociais) de enfrentamento à pobreza, pelo menos nos últimos anos do século XX e, de forma mais expressiva, nas primeiras décadas do século XXI. Mesmo considerando as distintas perspectivas teóricas sobre a pobreza, ao longo deste texto apresenta-se uma discussão sobre as experiências locais e a expressão do fenômeno da pobreza rural para o entendimento de realidades específicas no Brasil, notadamente, as experiências locais no Vale do Jequitinhonha, estado de Minas Gerais, Brasil.

Em um país marcado por profundas desigualdades regionais, tanto sociais quanto econômicas, as famílias residentes em áreas rurais são o ponto de partida para o entendimento do fenômeno da pobreza econômica, mas também para a compreensão da ampliação de políticas sociais, dentre elas, o Programa Bolsa Família (PBF). Embora a pobreza no Brasil seja um fenômeno presente em distintas realidades, sua distribuição tem um forte elemento espacial: em termos relativos, ela está concentrada no meio rural ${ }^{1}$.

Nos anos recentes, sobretudo após 2003, difundiu-se no Brasil um conjunto de pesquisas e relatórios técnicos que apontam para transformações sociais e econômicas que estariam em decurso no país. Uma das principais mudanças apontadas diz respeito à redução dos índices de pobreza e de desigualdade, sobretudo, nos primeiros anos do século XXI. Tal fato, segundo os dados, está associado à ampliação das políticas públicas, entre elas, as de transferência direta de renda aos domicílios mais pobres do país, localizados em regiões com baixo dinamismo econômico e alto índice de problemas sociais.

Este texto é uma compilação de um capítulo denominado de "estado e sociedade: políticas sociais e suas incidências nos lugares de vida" da tese de doutorado intitulada "Entre

\footnotetext{
${ }^{1}$ Ainda que a pobreza seja um fenômeno recorrente em todo o país, e em seus dois mundos (o rural e o urbano), em termos relativos, a pobreza rural é consideravelmente mais expressiva no Brasil. Em 2009, dos 30,7 milhões de pessoas que residem no meio rural, 8,4 milhões eram classificadas como pobres (PNAD, 2009). A distribuição espacial da pobreza apontava que $54 \%$ da população brasileira rural eram pobres economicamente.
} 
trânsitos permanentes e permanências transitórias: estudo sobre a reprodução social de famílias rurais pobres em Itinga, Minas Gerais, Brasil”. Esta foi defendida em 2016 no Programa de Pós-Graduação em Geografia (PPGEO) da Faculdade de Ciências e Tecnologia da Universidade Estadual Paulista (FCT/UNESP). Baseada, sobretudo, em metodologias qualitativas na produção de evidências, principalmente entrevista abertas, de forma sintética, este texto tratará sobre o processo de ampliação de políticas sociais em regiões carentes e os impactos destas nas condições de vida de famílias pobres residentes em áreas rurais do estado de Minas Gerais. Pela complexidade do debate proposto este artigo não tem pretensão de esgotar a referida discussão. Com esse texto espera-se contribuir para o debate (nem sempre consensual) sobre os impactos das políticas sociais, sobretudo nas condições de vida dos mais pobres economicamente.

\section{Estado e sociedade: o Sistema de Proteção Social no Brasil}

O Sistema de Proteção Social brasileiro, com ações governamentais concentradas nas áreas relativas à saúde, educação, assistência social, suplementação alimentar e programas habitacionais, começou a ser construído no período pós-guerra, ganhando maior relevância no ano de 1964 (MATTEI, 2003). Na experiência brasileira, as políticas sociais sempre receberam menos ênfase em relação às estratégias de desenvolvimento econômico do país. Ao longo do período militar, por exemplo, mesmo tendo havido expansão nos gastos de recursos públicos na esfera social em comparação aos anos anteriores, o sistema de proteção social permaneceu ligado às lógicas da política econômica nacional (HENRIQUES, 1999).

No Brasil, o período entre 1964 e 1988 foi conhecido como a época de aplicação de uma estratégia conservadora que "combinava a expansão da oferta de serviços com a centralização do processo decisório e com a regressividade dos mecanismos de financiamento, processo esse assentado no uso quase exclusivo de recursos de natureza fiscal” (MATTEI, 2003, p. 107). Dessa forma, o caráter redistributivo do Sistema de Proteção 
Social foi consideravelmente limitado, e este é um dos fatores responsáveis pelos indicadores de concentração de renda no referido período².

Estando o poder de decisão concentrado na esfera do governo federal, sob um regime de exceção, a ausência do controle social e da participação popular ou de representantes da sociedade no processo de elaboração e condução das políticas sociais "possibilitaram ao Estado a adoção de um sistema que, com o passar do tempo, foi sendo tomado por interesses particulares e clientelistas, com impactos negativos sobre o próprio resultado das políticas sociais" (MATTEI, p. 107 2003). Esse modelo de intervenção estatal começou a esgotar-se na década de 1980. A crise financeira internacional, seus reflexos no Brasil e o colapso do regime militar contribuíram para esse esgotamento. Com os reflexos da crise financeira da década 1980 e o fim do regime militar, houve no país o aumento, ou maior visibilidade, das demandas sociais, entre elas a necessidade de criação de políticas, programas e ações por parte do poder público tendo como centralidade o combate da pobreza e da pobreza extrema e seus efeitos agregados, não apenas, mas dentre eles, o fenômeno da fome. Como em outras experiências, a exemplo do que ocorreu em Portugal com o fim do Estado Novo, no Brasil, após o retorno à normalidade institucional (fim do período da ditatura miliar entre 1964 e 1985) e com a eleição de governos não ditatoriais, as demandas sociais começaram a entrar nas agendas nacionais, entre elas as discussões relativas ao Sistema Nacional de Proteção Social, as assimetrias sociais e a questão da pobreza econômica.

Um dos reflexos do fenômeno social e político referido no parágrafo anterior está na própria Constituição Federal de 1988, que contém um capítulo específico sobre seguridade social e as questões relativas à saúde, previdência e assistência social, direcionando ao Estado a responsabilidade de organizar o Sistema Nacional de Proteção Social (FAGNANI, 1999; MATTEI, 2013). Entre os princípios norteadores desse sistema, o texto legal estabelece a universalidade da cobertura, a equivalência dos benefícios e dos serviços às populações rurais e urbanas, as distintas formas de beneficiamento e mecanismos

\footnotetext{
${ }^{2}$ Em 1960, os 10\% mais ricos da população brasileira detinham 39\% da renda nacional. Em 1980, esse indicador subiu para 51\%. Com algumas pequenas variações, essa alta concentração de renda permanece como parte da realidade brasileira. Em 1960, 20\% dos brasileiros mais pobres tinham 3,9\% da renda nacional. Em 1980, os mesmos $20 \%$ concentravam apenas 2,8\% da renda que era produzida no Brasil. Em 1990, o Brasil chegou a deter a pior distribuição de renda em todo o mundo, pois enquanto os $10 \%$ dos mais ricos ficavam com mais da metade da riqueza nacional, os $10 \%$ mais pobres ficavam com apenas 0,6\% (HOFMANN, 2002).
} 
democráticos de gestão. Relativo à esfera financeira, foram definidas como fontes de financiamento do referido sistema "as contribuições dos empregados e dos empregadores, o Fundo Nacional de Investimento Social (FINSOCIAL), a parcela dos lucros líquidos das empresas, a receita percentual de jogos e as parcelas dos impostos arrecadados pelo governo" (MATTEI, p.108, 2013). Entretanto, o processo de implementação do novo sistema de seguridade social foi caracterizado por uma fragmentação política da aliança democrática, pelo clientelismo político e pela corrupção, elementos que contribuíram para a pouca eficácia das ações sociais adotadas nos períodos posteriores à Constituição de 1988, o que significou uma estrutura social brasileira permanentemente marcada por altíssimos índices de pobreza econômica e miséria.

Em 1980, a população total do Brasil era de 118,2 milhões de pessoas, sendo que 54,5 milhões $(46,1 \%)$ tinham rendimento per capita que não ultrapassava 0,5 salário mínimo, considerando os valores referentes a outubro de 1981 (ou 0,5 SM), e 26,6 milhões (22,5\%) tinham um rendimento per capita que não ultrapassava um quarto daquele salário mínimo, ou seja, eram pessoas classificadas como extremamente pobres, conforme o critério do rendimento familiar per capita. Em termos percentuais, os valores para 1990 não eram tão diferentes. De uma população total de 144,4 milhões de pessoas, 63,2 milhões $(43,8 \%)$ tinham rendimento per capita igual ou inferior a 0,5 salário mínimo, enquanto o rendimento per capita de 32,9 milhões $(22,8 \%)$ não ultrapassava um quarto daquele salário mínimo, ou seja, estavam em contexto de pobreza extrema.

Entretanto, mesmo com este cenário, tanto no governo do presidente Fernando Collor de Melo (1990-1992) quanto no de Itamar Franco (1993-1994), o foco das ações se concentrou na redução da presença do Estado na vida econômica e social. Trata-se de um período chamado de neoliberalismo "à moda brasileira", implementado por forças políticas conservadoras e com falsas promessas direcionadas aos brasileiros excluídos socialmente. No âmbito das políticas sociais, criaram-se dificuldades para o funcionamento dos direitos da sociedade explicitados na Constituição de 1988, principalmente devido ao adiamento da implementação de uma legislação complementar que os viabilizasse (IVO, 2008).

Entre 1995 e 2002, o governo de Fernando Henrique Cardoso foi marcado por uma estabilidade baseada nos preceitos do ajuste econômico proposto pelo Consenso de Washington, tendo como elementos centrais a desregulamentação dos mercados, a 
liberalização comercial e a reforma do Estado. Devido a essas circunstâncias, foi possível realizar reformas nos programas de seguridade social. A retomada do crescimento econômico e as mudanças no papel do Estado foram entendidos como aspectos essenciais para a obtenção de melhorias na esfera social (MATTEI, 2013). Entretanto, o governo FHC encontrava-se diante de um impasse: por um lado, havia a Constituição Federal, que estabelecia o direito do cidadão a saúde, educação, previdência e assistência das políticas sociais e o dever do Estado em prover esses serviços; por outro, a perspectiva neoliberal sob a qual os gastos públicos para atender as camadas mais carentes da população deveriam ser focalizados e selecionados. Na perspectiva de focalização e seletividade nos gastos sociais, o governo FHC lança o Programa Brasileiro de Desenvolvimento Social (PBDS) com um conjunto de políticas focalizadas no combate à pobreza, extrema miséria e à fome aguda. Essas políticas de combate à pobreza focalizam suas ações em critérios técnicos baseados em princípios de necessidade e eficácia, visando a descentralizar competências entre as distintas esferas do poder público (União, estados e municípios). No cenário nacional, porém, o baixo crescimento econômico e a fragilidade acerca das fontes de recursos contribuíram para a permanência das desigualdades sociais e de renda na estrutura populacional brasileira.

No entanto, como fruto de uma discussão que se estabeleceu no campo técnico, com ênfase na diminuição das desigualdades de renda no Brasil, ao longo da década de 1990 mesmo que o período fosse caracterizado pelo desencontro e pela incompatibilidade entre os programas de ajuste macroeconômico em decurso e as estratégias de desenvolvimento social do governo (FAGNANI, 1999), agravados pelas restrições relativas ao crescimento econômico que impactava o financiamento do sistema social de proteção começam a ocorrer algumas experiências pontuais de transferência direta de renda uma medida paliativa na tentativa de diminuir principalmente a extrema pobreza. Experimentos pioneiros foram realizados nos municípios paulistas de Campinas, Santos e Ribeirão Preto com programas de transferências de renda orientados a garantir uma Renda Básica de Cidadania (RBC), como uma tentativa de erradicar a pobreza e a miséria (SILVA \& SILVA, 2007).

No Distrito Federal, entre 1995-1998, foi implantado um programa de transferência direta de renda condicionada, o "Bolsa para Educação", que exigia das famílias beneficiárias a 
matrícula e a permanência dos filhos nas escolas. Entretanto, essas experiências careciam de condições técnicas, operacionais ou financeiras (LAVINAS, 1998; ROCHA, 2008). Para se ter uma ideia, entre 1995 e 1998, as despesas financeiras da União (juros, encargos e amortização da dívida externa e interna) aumentaram de $37 \%$ para $58 \%$, e os gastos sociais, de 25,5\% para 26\% (FAGNANI, 1999; MATTEI, 2013).

O que houve no cenário nacional foram ações muito pontuais e frágeis no combate à pobreza e à miséria. Utilizando o critério de salário mínimo, na década de 1990, os índices de pobreza e miséria eram consideravelmente altos, e o que estava em questão, entre tantos outros elementos agregados à pobreza, era a inseguridade alimentar e uma das expressões mais basilares da pobreza, a fome. Fome que não era e não deve ser entendida como uma ausência global de alimentos, mas relacionada à pobreza de grande parte da população brasileira (HOFFMANN, 1995).

No Brasil, os dados relativos à distribuição de renda presentes na Pesquisa Nacional por Amostra de Domicílios (PNAD, 2013), mostra a permanência de uma profunda desigualdade no país, mesmo após uma distribuição de renda, mas que foi consideravelmente tímida. No início do século XXI, a apropriação da renda por parte da faixa dos $10 \%$ mais ricos passou de 47,44\% em 2001 para 41,55\% em 2013. Por outro lado, entre os que estão nas faixas 50\% mais baixas passaram de $12,6 \%$ para $16,41 \%$. Em 2013, 15,09\% da população brasileira era considerada pobre. Em 2001, essa taxa representava 35,09\%. No ano de 2003, a gestão dos programas de transferência de renda era deficitária e este ponto refletia na inclusão e/ou exclusão das famílias nos programas sociais. Com problemas de comunicação entre os diferentes órgãos e desencontros entre um conjunto de programas, mas com mesmo foco, famílias em uma mesma condição de precariedade poderiam receber um benefício, todos os benefícios ou mesmo ser excluída da rede brasileira de proteção social. Nesse sentido, foi instituído no ano de 2003, o Programa Bolsa Família, que unificava todos os programas sociais de transferência de renda (Bolsa Escola, Bolsa Alimentação, Cartão Alimentação e Auxílio Gás). Surgiu com a proposta de melhorar a identificação dos beneficiários, agilizar a liberação de recursos, reduzir os entraves burocráticos e facilitar a transparência no destino dos recursos públicos. Com uma proposta mais ambiciosa, esta política social, além de integrar o Fome Zero e um conjunto de benefícios surge com a ambição de combater a fome e a miséria e promover a emancipação das famílias mais pobres (BRASIL, 2013). 
Há, na experiência brasileira, a mobilização de um conjunto de setores, tais como o empresariado brasileiro, a mídia impressa e televisionada, o terceiro setor (que não faz parte do mercado e do Estado) e a própria sociedade civil, para o enfrentamento da pobreza econômica. Entretanto, é o Estado, em suas diferentes esferas (União, estados e municípios), que tem apresentado experiências mais relevantes para o enfrentamento da pobreza. O papel do Estado tem aparecido como um elemento central de diferenciação na proposição e implementação de um conjunto de políticas no enfrentamento da pobreza.

Na segunda metade dos anos 2000 , ocorreu no país um período de relevante dinamismo econômico e, ao mesmo tempo, expressiva redução da pobreza e no crescimento dos rendimentos per capita dos domicílios. Entre 2003 a 2009 o número de pobres caiu de 36 para 23 milhões de pessoas. No meio rural, onde a pobreza relativamente é mais expressiva, houve uma redução de 13 para 9 milhões, ou seja, uma queda de 31 \% no número de pobres (IBGE/POF, 2003; 2009). A redução da pobreza foi resultado de uma variação positiva dos rendimentos em todos os segmentos sociais. Relativamente, a renda per capita das famílias mais pobres foi a que mais cresceu entre 2003 e 2009, de $R \$ 230$ para $R \$$ $326 /$ mês, um crescimento $42 \%$, índice superior ao crescimento de $20 \%$ da renda per capita urbana. O crescimento da renda per capita mais expressiva entre os mais pobres é reflexo não apenas da distribuição direta de renda. É resultado também de uma expressiva valorização do salário mínimo para o referido período (BARROS et al., 2007). Entre 2003 e 2009, a renda per capita cresceu $39 \%$ entre os mais pobres urbanos e apenas $14 \%$ entre os $10 \%$ mais ricos urbanos. No meio rural, o crescimento foi de $63 \%$ para os $40 \%$ mais pobres e de $32 \%$ para os $10 \%$ mais ricos.

Os indicadores apontam que as famílias pobres passaram por maior crescimento de seus rendimentos per capita. Entretanto, as desigualdades permanecem na medida em que o rendimento per capita dos $10 \%$ mais ricos é quase 20 vezes superior aos dos $40 \%$ mais pobres nos domicílios urbanos e 18 vezes superior aos domicílios rurais (IBGE,2009).

Os pobres, enquanto uma categoria social transitória, diversificada e multifacetada são grupos sociais que, em grande medida, não tem uma renda regular e acessam de forma precária as infraestruturas sociais, sobretudo relativas à saúde e educação, como é o caso das famílias residentes em localidades isoladas em Itinga, no Vale do Jequitinhonha. São indivíduos ou famílias que, em maior ou menor grau, são os despossuídos da sociedade 
capitalista contemporânea. A partir desses critérios, os pobres são entendidos como carentes e excluídos.

\section{Políticas sociais, intervenção no combate à pobreza e as rendas não-agrícolas}

O Programa Bolsa Família (PBF), no contexto de combate à pobreza, surge com a proposição de articular pelo menos três pontos considerados basilares na tentativa de eliminação da fome e da pobreza: promoção de redução imediata da pobreza através da transferência direta de renda; ampliação ou reforço dos direitos sociais básicos no âmbito da saúde e da educação; e coordenação de um conjunto de programas complementares, focalizado em famílias inseridas num contexto de vulnerabilidade social e/ou pobreza. Entre esses programas complementares, há os relacionados à geração de trabalho e renda, alfabetização de adultos, fornecimento de registro civil etc. (BRASIL, 2004). A articulação da transferência direta de rendimento com programas estruturantes, principalmente voltados à educação, saúde e trabalho (SILVA \& SILVA, 2007), representa, portanto, uma possibilidade de ruptura com um ciclo geracional de pobreza (SIQUEIRA, 2007). Ao ser incorporado ao Programa Fome Zero, o PBF, pelo menos no âmbito das propostas, busca assegurar a parcela da população brasileira mais vulnerável à fome e localizada na base da estrutura social nacional, o acesso à alimentação, a erradicação da extrema pobreza/miséria e a conquista da cidadania. De forma geral, o combate à fome, à pobreza e às assimetrias sociais mediante as transferências diretas de renda, acompanhadas de um conjunto de serviços sociais basilares, sobretudo saúde, educação e assistência social, são proposições governamentais para a inclusão social dos mais pobres. De forma mais audaciosa, o PBF intenta possibilitar a emancipação social das famílias beneficiárias e a construção de oportunidades para que essas pessoas saiam de uma condição de miséria/extrema pobreza ou até mesmo de um contexto de vulnerabilidade social.

O Programa Bolsa Família é uma das maiores iniciativas de combate à pobreza e à miséria no mundo. Tendo como público-alvo famílias com rendimento per capita mensal com renda 
“igual ou inferior a $\mathrm{R} \$ \mathbf{8 5 , 0 0}$ por pessoa (extremamente pobres) e às famílias com renda entre $\mathrm{R} \$ 85,01$ e $\mathrm{R} \$ 170,00$ por pessoa, e com crianças ou jovens de 0 a 17 ano", o programa complementava no ano de 2015 a renda de 13,9 milhões de domicílios com valor médio de $\mathrm{R} \$ 164,86$ por família, atingindo diretamente $1 / 4$ dos brasileiros (MDS, 2015). Seus principais objetivos são: 1) alívio imediato da miséria e da pobreza (transferência direta de renda), e certamente o objetivo mais conhecido do referido programa; 2) reforço ao exercício de direitos sociais basilares, com o intuito de contribuir para a ruptura do ciclo intergeneracional da pobreza (acesso à educação, à saúde e à assistência social); 3) apoio à geração de oportunidades para o desenvolvimento das famílias (ações complementares).

Em seus anos de existência, o PBF possibilitou retirar 36 milhões de pessoas da extrema pobreza mediante essas transferências diretas de renda. Entretanto, são consideravelmente altos os índices de pobreza e extrema pobreza no país, ainda que seja muito baixo o recorte de renda utilizado pelo governo brasileiro para identificar os pobres e focalizar políticas sociais a eles direcionadas. Enquanto em determinados países, como os componentes da União Europeia, a discussão maior gira em torno da exclusão social, no Brasil, uma das questões centrais continua sendo a necessidade de combate à miséria (extrema pobreza) e à fome, ou seja, as expressões mais basilares e mais cruéis da pobreza.

A fome como fenômeno social, pode ser compreendida em pelo menos três níveis: estrutural, específico e local (BATISTA, 2016). No nível estrutural, não é entendida necessariamente pela ausência de alimentos nos mercados globais, nacionais ou locais, mas como resultado direto da distribuição assimétrica de riquezas, notadamente, a concentração de renda e o desemprego. No nível específico, ela é decorrência de determinadas catástrofes naturais (secas/desertificações) ou sociais e políticas, tais como as guerras, que afetam diretamente o acesso das populações mais vulneráveis aos alimentos. No nível local, certas especificidades, tais como a baixa produção da agricultura para o autoconsumo, podem contribuir para a insegurança alimentar e a fome no âmbito micro.

No entanto, a avaliação do Programa Bolsa Família não é consensual, seja na sociedade brasileira em geral, no âmbito do campo acadêmico, ou no corpo técnico especializado - os assistentes sociais, por exemplo. Uma das principais críticas que a ele se faz diz respeito aos problemas que impedem a inclusão social dos beneficiários (SIQUEIRA, 2007), em especial a dificuldade de inserção no mercado de trabalho formal, que poderia ser a "porta de saída" 
da situação de pobreza e, consequentemente, da condição de beneficiário do programa, bem como a baixa qualidade dos serviços públicos, principalmente nas áreas da educação e da saúde. Entretanto, essa carência de qualidade dos serviços públicos é parte da própria rede de proteção brasileira que extrapola até mesmo as competências do PBF. Estudos locais no Brasil, como exemplo, nos estados do Rio Grande do Norte (sertão nordestino) e Minas Gerais (Norte e Nordeste) (SIQUEIRA, 2007; BATISTA, 2010) apontam, por exemplo, que a chegada do PBF em regiões empobrecidas, tais como o Nordeste do Brasil ou a Mesorregião Norte do Estado de Minas Gerais, contribuiu para o aumento do número de matrículas de jovens e crianças pobres em estabelecimentos de ensino, a diminuição da evasão escolar e a ampliação dos índices de vacinação, mas os serviços ofertados e acessados por essas pessoas são, em grande medida, consideravelmente precários, como ocorre em experiências locais, a exemplo de Itinga (MG).

A condicionalidade da permanência de jovens e crianças em instituições escolares para a obtenção e a manutenção do benefício é passível de críticas na medida em que essa permanência é entendida pelo beneficiário como meio para o recebimento de uma renda e não necessariamente como o reconhecimento do papel e da importância da educação (SIQUEIRA, 2007). Mas, entre as famílias mais pobres, um dos reflexos do PBF, com a exigência de matrícula dos filhos em instituições de ensino, é que as crianças são afastadas de trabalhos pesados. Há autores que veem nisso uma inversão de valores, pois o que na essência é um direito passa a ser uma obrigatoriedade (SOARES, 2007), mas com o PBF, é possível às famílias retirarem seus filhos do trabalho na atividade agrícola (na roça) para se dedicarem aos estudos. E as evidências apontam que os índices de evasão são muito baixos.

Outra crítica que se faz ao PBF é que, ao selecionar os beneficiários a partir de níveis de renda muito baixos, restringe a inclusão de pessoas e/ou famílias vulneráveis no programa (SENNA et alii, 2007), representantes de estratos da sociedade que se encontram em distintas situações de vulnerabilidade. Retoma-se, assim, a questão do critério adotado para a seleção do público-alvo do programa, o qual, para muitos, não deveria ser rígido. Outra face do problema é que, num país marcado pela informalidade do mercado de trabalho, também pode ocorrer que famílias com renda acima do critério de inclusão sejam indevidamente incluídas no programa, visto não terem seus rendimentos contabilizados. Neste caso, porém, os valores transferidos geralmente são tão baixos que pouco alteram as 
condições das famílias pobres (SILVA \& SILVA, 2007). O impacto dos recursos é maior mesmo na redução da condição de miserabilidade de pessoas e famílias e da vulnerabilidade à insegurança alimentar.

Independente de como é avaliado, o PBF, um rendimento extrafamiliar, originário das transferências diretas de renda, é incorporado na economia doméstica e passa a ser parte das estratégias familiares de reprodução social. Seus recursos alteram a economia doméstica e, como primeiro impacto, se reflete no aumento quantitativo de alimento e, depois, na compra de eletrodomésticos e móveis financiados, movimentando as economias locais, sobretudo em Itinga e Araçuaí. O município de Itinga (mapa 1), localizado na microrregião de Araçuaí, no Vale do Jequitinhonha, detém duas características bem particulares que o diferenciam da maioria dos municípios brasileiros: 1ํ) o predomínio da população residente no meio rural; e $2^{\circ}$ ) a ocupação de maior parte de sua população ativa em atividades consideradas essencialmente agrícolas (relacionadas à produção animal e vegetal).

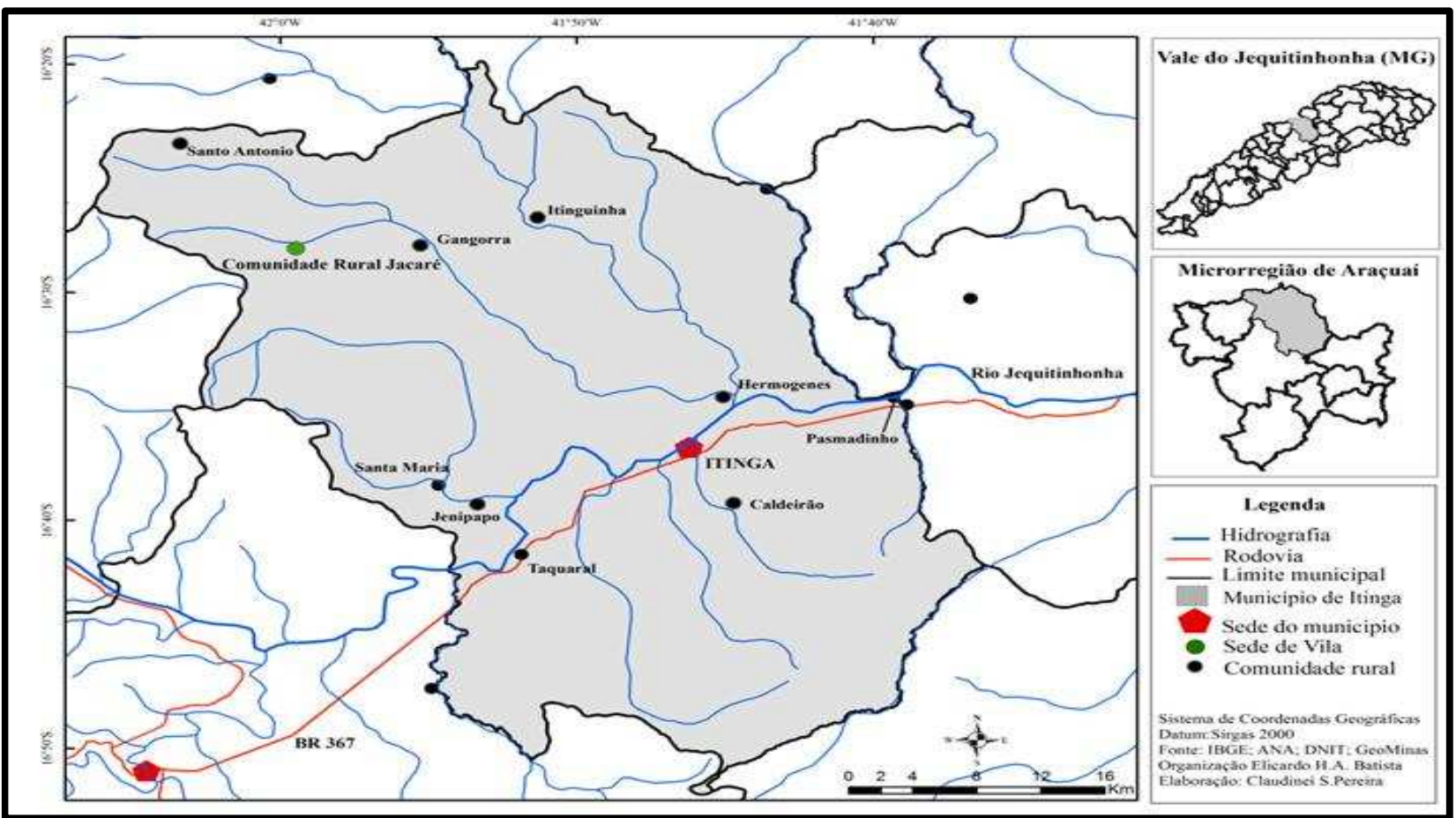

Mapa 1: Munícipio de Itinga (MG) e as áreas rurais. 
Além disso, o acesso a determinados bens, tais como roupas e sapatos, assim como melhorias nas residências, com a troca do telhado, pintura e o chão cimentado são algumas modificações pontuais que contribuem para uma percepção de que estão ocorrendo transformações em suas condições de vida, viabilizadas pelas transferências diretas de renda. Se, nos lugares de vida, há uma incerteza dos rendimentos, vivendo as pessoas permanentemente por um "fio", dedicando-se a uma agricultura para o autoconsumo, com baixa capitalização, elas dependem consideravelmente dos benefícios sociais que são parte essencial de suas estratégias de reprodução social. Para as famílias residente em rurais dedicando as atividades agrícolas (produção animal e vegetal), organizando o trabalho a partir da unidade familiar, que é simultaneamente unidade de produção agrícola e de consumo, na incerteza dos recursos monetários advindos da comercialização dos produtos agrícolas resultante das atividades na roça e no roçado, adotam involuntariamente novas estratégias de sobrevivência, ampliando o peso dos rendimentos dos benefícios sociais.

Comumente ao fato de serem famílias agrícolas, com a incerteza das rendas nos lares, a "ajuda" do governo passa a ter um forte peso na definição das estratégias de reprodução social das famílias. O PBF tem tanto um papel complementar ou suplementar no contexto dos rendimentos do grupo. Com o insucesso na atividade agrícola, o PBF passa a ser o principal rendimento monetário do grupo familiar. Em geral, nos anos de "safra" boa, grande parte da produção de farinha, feijão, milho, rapadura e gordura de porco é estocada pelas famílias. Mas, anos seguidos com longas estiagens e um menor tempo das águas diminuem os estoques que as famílias possuem em suas dispensas. Na impossibilidade de trocar ou doar alimentos entre os vizinhos, recorrem aos mercadinhos com a renda dos benefícios sociais. A dependência do Programa Bolsa Família entre famílias pobres também é ampliada quando não há idosos residindo em seus lares. Como já demonstrado em outra oportunidade, as aposentadorias rurais e as pensões, por terem o seu valor atrelado ao salário mínimo vigente no país, além de estabilizar a renda familiar, viabilizam também a melhoria das condições de vida e a compra de bens materiais duráveis (carros, móveis e motos) e de consumo imediato (alimentos, roupas, calçados, entre outros), sendo que os principais gastos do benefício são com o consumo de alimentos, seguido do pagamento de tarifas de água e luz (BATISTA, 2010). 
Em lugares com limitadas possibilidades de mobilidade social mediante o trabalho (agrícola e não agrícola), a presença de um aposentado rural em lares com poucos dependentes dessa renda é até mesmo um elemento de diferenciação social e interfere indiretamente nos arranjos familiares, com a valorização do idoso que, de dependente a provedor, passa a ser disputado pelas famílias. Ter um idoso aposentado no lar é uma forma de ter também um rendimento regular ao longo dos meses do ano (BELTRÃO et alii, 2005). Geralmente as crianças e os idosos são duas categorias vulneráveis à pobreza, mas, com as aposentarias rurais, os mais velhos conseguem influenciar diretamente nas condições de vida dos membros de sua casa e até mesmo ampliar o investimento na atividade agrícola, com a compra de maquinários que serão operados pelos membros da família em idade ativa. Os idosos saudáveis tendem também a continuar na atividade agrícola, mesmo após a obtenção do seu benefício, pois a permanência no trabalho na roça é que dá sentido à existência dessas pessoas. Entretanto, em locais muito pobres e com limitadas possibilidades de ter acesso a uma renda monetária certa, os idosos não conseguem proporcionar uma considerável melhoria nas condições de vida de suas famílias, como exemplo, nas residências, nas compras de móveis e eletrodomésticos, quando há muitos dependentes a uma única fonte certa de renda.

De fato, a estabilização dos ganhos monetários não contributivos tem maior poder para efetivar essa mudança em contextos em que há um menor número de dependentes dos idosos. Não se trata, porém, de profundas alterações ocupacionais. São famílias de agricultores, descapitalizados e marginalizados, que conseguem estabilização da renda mediante a presença do Estado no espaço intradoméstico, com o recebimento dos benefícios sociais. Ainda assim, considerando que a maior parte das pessoas é dependente da atividade agrícola, esses benefícios tendem a ter um impacto indireto em sua retenção nos seus lugares de vida e em melhores condições materiais de existência. Um dos problemas relativos às áreas rurais de Itinga é que os rendimentos monetários não relacionados à atividade agrícola são, em sua maioria, decorrentes de transferências diretas de renda dirigidas aos mais pobres, aos idosos ou a portadores de deficiências físicas e mentais (aposentadorias, pensões e benefícios de prestação continuada), visto que o mercado de trabalho representa uma contingência que limita consideravelmente as opções nos locais de origem. Os trabalhos não agrícolas, restritos aos escassos postos de trabalho 
no funcionalismo público, ou a pequenos negócios que comercializam alimentos, dos quais se ocupam geralmente pessoas do próprio núcleo familiar, não dão às pessoas do lugar possibilidades de escolha. Ou seja, é muito raro haver residentes nas áreas rurais em idade ativa, ocupados em atividades não agrícolas, seja em tempo integral, seja em tempo parcial.

Se o mercado de trabalho no entorno das pequenas propriedades rurais pudesse absorver alguns membros da família, sobretudo os jovens rurais, haveria como solucionar o desencontro entre os membros em idade ativa presentes nos lares e a pouca demanda para o trabalho da atividade agrícola ao longo do ano, principalmente, mas não apenas, durante os períodos de seca, quando diminui o trabalho familiar na roça e no roçado. Entretanto, para que isso se concretizasse seria necessária a ampliação do fenômeno das ocupações em atividades não agrícolas nas proximidades das comunidades, ocorrendo alterações nos mercados de trabalho rurais, o que de fato, não ocorre, ou ocorre pontual e insatisfatoriamente, como já mencionado. Como afirma Kageyama (2003, p.58), as rendas não agrícolas são importantes, na medida em que "podem viabilizar a sobrevivência da agricultura familiar no capitalismo, contribuir para a fixação da população no campo e aliviar a pobreza rural".

A combinação de múltiplas inserções ocupacionais dos membros pertencentes a uma mesma família é dificultada pelo ambiente social e econômico em que se inserem, em virtude da inexistência de postos de trabalho, visto não haver ali indústrias, grandes construções ou estabelecimentos de prestação de serviços, etc. A possibilidade de a família ter uma ou mais fontes de renda (combinação de uma ou mais inserções laborais) depende, portanto, de um conjunto de variáveis e fatores existentes tanto no espaço intradoméstico (número de trabalhadores disponíveis), quanto no espaço circundante (oferta de empregos). Como consequência, em famílias compostas por muitos jovens, cuja atividade agrícola não os absorve satisfatoriamente, essa diversificação das fontes de renda só é possível e, muitas vezes viabilizada, pela migração temporária ou definitiva de alguns dos membros dos grupos familiares.

Para as pessoas do lugar, o principal problema não está na pobreza, na miséria ou na falta de infraestrutura social, mas na ausência de empregos que estabilizem a renda e que, no imaginário social, representaria uma possibilidade de melhorar suas condições de vida. Essa visão é reforçada pelos próprios beneficiários do PBF, que entendem o caráter transitório do 
programa e, também, que o baixo valor do benefício, visto como uma ajuda, não resolve satisfatoriamente às necessidades das famílias. A inserção de membros das famílias em atividades não agrícolas, configurando novos modos de ocupação da força de trabalho, poderia diminuir a vulnerabilidade social a que estão expostas. Embora alguns membros das famílias assumam a migração como forma de obter emprego e renda, a fim de ajudar os que ficaram no lugar de origem, os custos nos lugares de destino (aluguéis, contas de água, luz, alimentação, transporte etc.) acabam por reduzir muito essa ajuda. Consequentemente, os recursos dos benefícios sociais restam como a única certeza de renda para dar conta das necessidades cotidianas.

Entre as famílias pesquisadas (35), 20 tornaram-se beneficiárias no ano de 2003, ou seja, na primeira experiência do programa, e 15 entre os anos de 2005 e 2007. Em todos os casos, não há uma previsão sobre a devolução dos cartões, o que deve ser entendido como uma falta de perspectiva para a "saída" da situação de pobreza. Isoladas e com dificuldades de acesso ao também escasso mercado de trabalho na sede urbana do município de Itinga, essas famílias dependem do recurso do PBF que, geralmente, é incorporado no orçamento familiar para a resolução de problemas do cotidiano, sobretudo, mas não apenas, para a compra de alimentos e o pagamento da conta de energia elétrica. No ano de 2015, com valores que variavam entre $\mathrm{R} \$ 112,00$ (valor mais baixo) e $\mathrm{R} \$ 360,00$, (valor mais alto), eram as mulheres que administram o rendimento. O fato de o cartão do Bolsa Família estar em nome das mulheres tem em si um forte peso simbólico. Em outras experiências locais no Brasil, as mulheres são consideradas as melhores gestoras da econômica doméstica, diferente dos seus maridos que, acredita-se, ou não sabem realizar as compras adequadas às necessidades da família, ou provavelmente gastariam os recursos com bebidas (REGO \& PIZANI, 2013).

Nas áreas rurais de Itinga, ter um cartão bancário no próprio nome aponta para outros fatores, além da gestão da economia doméstica. Mulheres analfabetas ou semiescolarizadas, com média de três anos de estudos, têm pela primeira vez a condição de, após a contração do matrimônio, acessarem uma renda que elas administram. As mulheres, invisíveis, recolhidas em grande parte do ano nas suas casas rurais, pois em geral não migram, e o seu trabalho se restringe às lides domésticas e/ou ao trabalho na roça, começam a circular por espaços públicos, sobretudo nos bancos e nos pequenos 
mercadinhos locais. Dessa forma, adquirem visibilidade. Com um significado mais importante e profundo, administrar a renda familiar é papel apontado pela literatura como condição de empoderamento dessas mulheres pobres (REGO \& PIZANI, 2013). Com o PBF, elas têm uma maior liberdade nas escolhas dos bens de consumo familiar. Entretanto, ao mesmo tempo em que há um recurso que é complementar a renda familiar, este consumo é limitado pelos valores do Programa Bolsa Família. Com a ausência de salários regulares, é no PBF que elas se apoiam na certeza de ter uma renda que podem contar para garantir o suprimento das necessidades básicas do grupo familiar.

No caso dos beneficiários do PBF, o uso do dinheiro na compra de bens considerados essenciais à vida traz a percepção de aumento do conforto e melhoria das condições de vida no lugar de origem, como ter energia elétrica e uma geladeira, por exemplo. A compra de roupas, sapatos, produtos de higiene e alimentos e de produtos que as famílias beneficiárias conseguem acessar nos mercadinhos locais permite às pessoas pobres afirmarem que o PBF mudou sua vida positivamente. É um dinheiro que dá mais liberdade de escolhas, mesmo que sejam limitadas, devido ao valor do benefício que varia conforme o número de filhos. Mas, para pessoas com rendimentos incertos e, não raro, até mesmo inexistentes, o Programa Bolsa Família representa poder escolher determinados produtos, como por exemplo, iogurte e bolacha recheada. O acesso a um determinado rendimento somado a facilidades creditícias possibilitam aos pobres a aquisição de determinados bens, como televisão, geladeira e telefone celular. Os modos, os meios e condições de vida e até novas formas de sociabilidade (com o uso de celulares) são fortemente influenciados pela relação entre Estado (e suas políticas específicas para os pobres) e a sociedade (neste caso os mais pobres). O aumento do nível de educação formal, todavia, é seguramente a parte mais difícil e invisível das condicionalidades do Programa Bolsa Família. Além de um relativo aumento no poder de compra dos pobres, com o Programa Bolsa Família, as mudanças geradas pelo fornecimento de energia elétrica - Programa Luz para Todos - e de água - Programa Mais Cisternas - são alguns indicativos que os próprios grupos sociais classificados como os pobres do Jequitinhonha (e do país) acionam, para avaliarem uma melhora significativa em suas condições de vida.

Sendo a pobreza (econômica) um fenômeno multidimensional, seu enfrentamento requer uma articulação de diferentes tipos de políticas, mas o PBF é a principal delas e com maior 
expressão no combate à pobreza. Nos relatos das famílias do Vale do Jequitinhonha, a descrição de suas condições de vida contemplam sempre dois momentos, o anterior e o posterior à chegada do Programa Bolsa Família. Antes de 2003, quando não havia o repasse de dinheiro a essas famílias como tentativa de eliminação da pobreza, as privações relativas ao acesso a alimentos eram uma constante e, não raro, estava presente o próprio fenômeno da fome. Nem sempre era possível obter o alimento por meio do trabalho na terra, da produção animal e vegetal para o autoconsumo. O próprio abastecimento familiar a partir da produção destinada ao autoconsumo limitou, historicamente, o acesso das famílias ao alimento.

Os repasses do Programa Bolsa Família apresentaram uma expressividade maior para as economias de grupos familiares em que não havia nenhum aposentado e/ou de cujo pequeno patrimônio territorial fundiário não conseguiam retirar o necessário para o autoconsumo. É importante ressaltar, todavia, que juntamente com o PBF, a produção para o autoconsumo (produção não monetária) desempenha papel relevante na redução da vulnerabilidade alimentar do grupo familiar (plantar para comer).

A natureza do ciclo familiar favorece (ou não) o acesso a um conjunto de rendimentos que são importantes para a própria estratégia de reprodução social do grupo: I- Famílias compostas por um maior número de crianças e jovens tendem a ser beneficiárias do Programa Bolsa Família. Entretanto, ainda que os recursos sejam proporcionais ao número de dependentes, há uma grande pulverização dos rendimentos, o que mantém as difíceis condições materiais de existência desse grupo. Nas famílias com muitas crianças em relação aos adultos em idade produtiva, há, portanto, uma possibilidade maior de o grupo familiar estar vulnerável a uma condição de pobreza (econômica e material). Com isso, percebe-se que a natureza do ciclo de vida interfere consideravelmente nas trajetórias e condições de vida das famílias. II- Famílias com idosos tendem a ter, no espaço intradoméstico, benefícios da previdência rural. De qualquer modo, a vulnerabilidade é maior entre famílias com muitas crianças, que entre famílias com idosos. Estas conseguem proporcionar melhores condições de vida aos seus membros que aquelas, com muitos membros dependentes e beneficiária apenas do Programa Bolsa Família (PBF), por exemplo. É comum, entre as famílias pobres, o acúmulo de benefícios sociais (aposentadorias rurais e o Bolsa Família). Entretanto, diferente de outras experiências locais, como no norte do Estado de Minas 
Gerais (BATISTA, 2010), as aposentadorias rurais em Itinga têm peso menor na melhoria das condições de vida das famílias do lugar, de que é exemplo a de dona Antônia, uma agricultura de 75 anos, da Comunidade Rural dos Hermógenes, matriarca de uma família cujos 26 membros dependem da renda do PBF e de sua aposentadoria.Ainda que não haja uma grande diferença entre as residências nas comunidades, no que concerne à parte física, as casas das famílias exclusivamente agrícolas e que não podem contar com outra fonte de rendimento são as mais precárias. Como há forte relação entre acesso a benefícios sociais e ciclo de vida familiar, as pessoas do lugar almejam atingir a idade para a obtenção da aposentadoria, vista como uma possibilidade de melhoria nas condições de vidas. Em síntese, analisando as fases do ciclo familiar, percebe-se que, ao contrário de famílias com muitas crianças ( 7 a 12, por exemplo), aquelas compostas por poucos membros (média de 5 pessoas), com indivíduos em idade ativa e/ou com idosos aposentados, tendem a melhorar sua condição de vida. O ciclo de vida familiar e poucos dependentes apontam para diferenciações nas condições de vida e até mesmo para distinções sociais entre as residências de uma mesma comunidade rural. As aposentadorias rurais e pensões garantem uma estabilização da renda familiar, possibilitando que as famílias melhorem suas residências, comprem bens materiais duráveis (carros e motos) e de consumo imediato (alimentos, roupas, calçados, entre outros), sendo que os principais gastos do benefício são com a compra de alimentos, seguidos dos custos da tarifa de energia. Além dos melhoramentos materiais que esses benefícios sociais proporcionam, eles acabam também por promover a composição de novos arranjos familiares, como por exemplo, a mudança do papel do idoso no seu próprio grupo, passando de "dependente a provedor" (BELTRÃO et alii, 2005) e a ser pessoa altamente desejada nos lares das famílias pobres. À medida que as aposentadorias e pensões influenciam na melhora da renda do indivíduo, ela também afeta as condições de vida dos corresidentes do beneficiário.

A reprodução social dessas famílias passa a ser consideravelmente influenciada pelo acesso às políticas públicas, que têm como efeito direto ou indireto a redução da pobreza. No geral, são esses os elementos centrais que interferem nos meios e condições de vida dessas famílias. Ou seja, a reprodução social é um processo em que determinada sociedade, mediante diversos mecanismos a partir do ambiente social e econômico na qual está inserida, reproduz suas mais diversas estruturas, mas fundamentalmente baseada em 
elementos externos aos grupos, como são os benefícios sociais. Em um universo social em que há altos índices de pobreza, tanto a melhora nas condições de vida quanto uma possível mudança na estrutura social (sobretudo pela saída da situação de miséria) são mais plausíveis no horizonte das famílias quando há no espaço familiar a presença do Estado, através principalmente de políticas públicas (particularmente as de caráter social). A satisfação das necessidades básicas dessas famílias (sobretudo no acesso aos alimentos), a posse de determinados bens (a garantia de certo nível de conforto) e o acesso a uma infraestrutura social (como educação e saúde) são atingidos principalmente em decorrência da presença do poder público nessas localidades.

Políticas focalizadas, como os programas de transferência de renda (Bolsa Família) e a aposentadoria rural, têm um impacto maior na redução da miséria. Ambas têm em comum o efeito imediato de inserir as famílias no mercado de consumo, ao possibilitar aos estratos mais pobres da sociedade o acesso a um determinado rendimento monetário. Por esse fato, nas regiões brasileiras em que há altos índices de pobreza econômica, o que se percebe com a chegada de políticas de transferências direta de renda (sobretudo o Programa Bolsa Família) e o acesso de um público (os pobres) a esses rendimentos, é o surgimento de mercados e lojas que comercializam eletrodomésticos. Mas, experiências locais no Brasil, como exemplo, no Vale do Jequitinhonha, Nordeste de minas Gerais, têm mostrado que o impacto da elevação do salário mínimo sobre a pobreza é maior que o de programas do tipo Bolsa Família, sobretudo para as pessoas com um campo de possibilidades limitado, entre outros motivos, pela pouca opção de trabalho ou de novas formas de ocupação.

Um dos principais dramas das pessoas que vivem em condições de miséria e pobreza no Vale do Jequitinhonha é a ausência de uma educação formal ou os conhecimentos técnicos que ampliem a possibilidade de inserção em distintos campos existentes no mercado de trabalho, sobretudo os empregados com carteira assinada. A baixa educação formal dificulta que as famílias mais pobres consigam trabalho que exija um conhecimento mais especializado. Para as famílias proprietárias de terra, que produzem grande parte do que consomem, mas, em pequenas quantidades, o Bolsa Família ajuda a "complementar a feira". O feijão, a farinha, as hortaliças, as frutas, o milho (para manter a criação de galinhas, porcos e o gado) raramente são comprados nas mercearias, pois são retirados da propriedade, ainda que sem muita regularidade. Produtos de limpeza e higiene pessoal, 
açúcar, arroz e outros itens industrializados são adquiridos com o benefício do PBF. No entanto, para as famílias que não possuem terra para o cultivo, residentes nas vilas e povoados, é o Bolsa Família que possibilita o acesso aos alimentos e a ajuda esporádica das famílias (nucleares e estendidas) e dos grupos de vizinhança. Para as famílias rurais agrícolas, a renda do Bolsa Família é amplamente reconhecida como um complemento à produção para o autoconsumo, inclusive quando o trabalho na agricultura é praticado pelos jovens.

Outro efeito da presença das transferências de renda em localidades tradicionalmente desassistidas pelo Estado é a nova configuração que se desenha nas relações de trabalho.

Para os pequenos proprietários de terra, sem acesso a uma renda fixa, era comum aceitar trabalhos precários, com baixa remuneração e, muitas vezes, apenas em troca de alimentos. O trabalho prestado aos fazendeiros pelos agregados implicava a ética do favor: uma retribuição por ter um lugar para viver e um pedaço de chão para trabalhar em seus roçados. Quando esse arranjo deixou de existir, ganhou força o trabalho do camarada, uma categoria de trabalhadores rurais diaristas, residentes nas vilas, povoados ou em suas pequenas propriedades, que prestam serviços aos fazendeiros locais, recebendo pagamento em dinheiro ou alimento. Trata-se de uma relação assimétrica, diferente das ajudas entre iguais nos trabalhos do roçado e roçadinho. Sem muito poder de barganha, os camaradas aceitavam o trabalho mediante acerto verbal sobre o pagamento que constituía, às vezes, a oferta de almoço e jantar. Entretanto, a chegada do PBF, que para muitas pessoas representou a primeira experiência de uma renda fixa, possibilitou aos trabalhadores locais negociar com os patrões o pagamento pelo trabalho de camarada. Como efeito positivo indireto do PBF, a mão de obra dos mais pobres tornou-se mais cara, pelo menos em determinadas localidades do país. Garantido o rendimento para a compra de alimentos, os trabalhadores passam a exigir remuneração melhor pelos trabalhos mais degradantes, como por exemplo, nas carvoarias. Se o contratante não paga bem pela diária é possível recusar a empreitada até que surja, ainda que temporário e pesado, um trabalho melhor remunerado. Mesmo nesse ambiente econômico, a posse do dinheiro dilui "obrigações costumeiras vinculadas ao caráter privado da relação pessoal: obrigação e prestação de serviços constitutivos da dependência pessoal entre pessoas que interagem, mas investidas de poder muito desigual" (REGO \& PIZANI, 2013, p.219). 
Os agricultores locais capitalizados, após a chegada do PBF, passaram a encontrar maior dificuldade para contratar trabalhadores fixos ou temporários. Conforme o Sr. Joaquim, um desses proprietários de terra entrevistado, o que ocorre é que as pessoas "não querem mais trabalhar na roça" e estão "mais preguiçosas". Acreditam que ao assistir as famílias, o PBF estaria causando a acomodação dos beneficiários em relação ao trabalho, uma espécie de "efeito preguiça". Ironicamente, os próprios grupos que criticam os pobres pela indolência/preguiça, são os mesmos que em geral tentam explorar essa mão de obra, não assinam suas carteiras de trabalho, pagam valores simbólicos pelas diárias e não querem, na ausência dessa mão de obra, realizar os serviços que os trabalhadores pobres realizam. Tanto nos trabalhos esporádicos como nos fixos, a carga horária e os valores pagos são definidos oralmente. Na região, um trabalhador recebe, em média, $\mathrm{R} \$ 15,00$ por dia para "roçar a manga", utilizando a foice, ou R\$ 8,00 para "descarregar" um forno de carvão. Esses valores variam conforme a demanda e, geralmente, são combinados previamente entre contratador e contratado. Um "tirador de leite" trabalha meio período, porém de domingo a domingo, recebendo menos que um salário mínimo, como é o caso de um jovem de 19 anos cujo ganho mensal é de $\mathrm{R} \$ 235,00$. Outro exemplo é o de Eugênia, de 27 anos, que trabalha como empregada doméstica de segunda a sábado em uma comunidade rural, recebendo mensalmente $\mathrm{R} \$ \mathbf{8 0 , 0 0}$. Segunda ela, aceita essa situação devido à impossibilidade de ter outra fonte de rendimento, mas planeja, tornando-se beneficiária do PBF, deixar o emprego de doméstica, pois "trabalha e sofre muito, mas ganha pouco".

Entre as diversas privações decorrentes da pobreza econômica, é consenso, entre os estudiosos desse fenômeno socioeconômico, que a fome é uma de suas faces mais duras. A partir dos relatos dos entrevistados, cujas trajetórias sociais são marcadas por privações diversas, incluindo a escassez de alimentos, é possível inferir que atualmente encontram-se em situação mais confortável, conformando um novo tempo. O "tempo da fome" e da "necessidade" corresponde ao período em que as famílias eram compostas por muitos dependentes e os benefícios sociais não existiam. Para os beneficiários do PBF, a vida é dividida entre o "antes" e o "depois" do acesso a essa política social. Ainda que o programa seja um complemento temporário, insuficiente para suprir todas as necessidades da família, permite ao menos mitigar o problema da insegurança alimentar. 
Essa mesma seletividade ocorre com as migrações temporárias. Com a possibilidade de ter uma renda nos lugares de vida, as pessoas tendem a evitar a migração para inserção em trabalhos precários, como por exemplo, nos fornos de carvão vegetal. Entretanto, mesmo exigindo um maior pagamento pelo seu trabalho, muitos desses beneficiários do Bolsa Família permanecem inseridos no mercado de trabalho informal. A tendência a permanecer mais tempo no lugar de vida, ao invés de optar pela migração, ainda que temporária, aponta que os rendimentos dos benefícios sociais interferem nas dinâmicas de mobilidade espacial, condicionando inclusive a permanência de populações rurais com fortes tendências migratórias em suas localidades de origem.

Entretanto, nessas localidades, a dificuldade de acesso ao mercado de trabalho e ao ensino formal têm sido um dos grandes entraves à eliminação da pobreza econômica no Brasil, um fenômeno socioeconômico multideterminado e multifacetado, ainda bastante expressivo no cotidiano das famílias. Nos últimos anos, período posterior à década de 1990, porém, a diminuição da miséria e da pobreza (fenômeno socioeconômico ainda persistente) e uma relativa melhora nas condições de vida das famílias pobres foram viabilizadas em decorrência da atuação do poder público, mediante políticas estruturais que possibilitaram às famílias o acesso à energia elétrica, água encanada e tratada, a melhoria nas condições de moradia, inclusive com a construção de banheiros privativos, bem como a "injeção" de dinheiro por meio de benefícios sociais, o que promoveu aumento quantitativo de bens das famílias e de itens relativos à alimentação. Entre as famílias pobres, quanto maior o "braço" do Estado no interior de seus lares, mais expressiva foi a melhora em suas condições de vida, seja através do Programa Bolsa Família ou de outras fontes de rendimento como a aposentadoria rural (baseada no salário mínimo nacional). A diversificação das fontes de rendimento não diretamente ligadas à produção animal e vegetal (atividades não agrícolas) certamente interfere nas condições de vida das famílias, constituindo um importante mecanismo de redução da pobreza. Apesar do amplo grau de cobertura do Programa Bolsa Família, a previdência rural e as pensões têm um efeito maior em termos de valores, por serem calculadas com base no salário mínimo, e a renda por elas obtida pode ser ainda mais significativa dependendo das características familiares, principalmente o número de dependentes que as compõem. 


\section{Considerações Finais}

Entre as famílias, localizadas na base da estrutura social que tem em seu cotidiano, os dramas das incertezas, sobretudo relativo à renda monetária, a universalização e o crescimento exponencial (ainda que extremamente insuficiente) das políticas sociais, são percebidas como um dos elementos fundamentais para avaliar essa melhoria de suas condições de vida. Entende-se que as políticas sociais, inclusive do governo Luiz Inácio Lula Da Silva, quando houve a maior saída das pessoas de uma condição de pobreza e extrema pobreza, tem tido um importante papel na dinamização das economias das famílias mais pobres, mesmo não tendo um efeito de impactar processos de mobilidade ascendente.

As políticas sociais, ao apropriar de uma pequena parcela dos recursos do Estado em benefícios dos mais pobres, com as transferências diretas de renda, têm impacto nos modos, meios e condições de vida dessas famílias, sobretudo, mas não apenas nos aspectos relativos aos alimentos e compra de certos bens que dão certo conforto e saída da condição de miséria, o que geralmente os tiram de uma condição de miséria, mas não necessariamente de pobreza. No geral, as políticas sociais (com forte expressão da política de aposentadoria rural e o Programa Bolsa Família) tem desempenhado um importante papel no sentido de redução da miséria no meio rural em questão. Rendimentos originários das transferências diretas de renda são incorporados às economias das famílias e passam a ser parte das estratégias familiares de reprodução social. Percebe-se que as políticas sociais possibilitam que as famílias em condições de miséria e pobreza tenham pelo menos um nível digno de vida, podendo inclusive ser mais seletivos na escolha de trabalhos temporários ou deter maior poder de negociação para obter pagamentos melhores. A obtenção do PBF impacta diretamente na economia familiar (fonte de rendimento estável) e nas condições materiais de vida, com a possibilidade de melhorias na residência e nas vestimentas, e de aquisição de bens de consumo, como geladeira e fogão. Com trajetórias sociais marcadas pela pobreza econômica, pela marginalidade e exclusão social nas experiências dos migrantes do trabalho precário, os rendimentos oriundos dos programas sociais aparecem como uma possibilidade de ter uma renda no lugar de vida, o que dentre outros efeitos, contribui para uma relativização da necessidade de migrar para se inserir em mercados de trabalho extremamente precários. Ao mesmo tempo em que há um forte peso dos benefícios sociais na possibilidade dessas famílias terem o acesso aos rendimentos, este 
fenômeno é um forte fator de peso na opção pela não migração e até mesmo na realização da migração de retorno, em uma região fortemente marcada pelas migrações, sobretudo, mas não apenas, a do tipo temporária. Os pobres, como consumidores, permanecem mais tempo em suas localidades e conseguem com os benefícios sociais injetar dinheiro na economia local. Contudo, esse processo é, em grande medida, amparado por programas sociais de transferência de renda. Nesse sentido, as mudanças mais significativas no âmbito local se dão no contexto de uma forte presença do Estado com seus programas sociais, sobretudo o Programa Bolsa Família (PBF). Pode-se dizer que os processos sociais, econômicos e até mesmo culturais são reconfigurados a partir do momento em que há a "presença" do poder público nos "mundos rurais" com altos índices de pobreza.

\section{Referências bibliográficas}

BATISTA, Elicardo Heber de Almeida. Entre trânsitos permanentes e permanências transitórias: estudo sobre a reprodução social de famílias rurais pobres em Itinga, Minas Gerais, Brasil, (Tese - doutorado em Geografia) Faculdade de Ciências e Tecnologia da Universidade Estadual Paulista (FCT/UNESP) Presidente Prudente, 2016. $374 \mathrm{p}$.

BELTRÃO, Kaizô.; CAMARANO, Ana; LEITÃo e MELLO, Juliana. Mudanças nas Condições de vida dos Idosos rurais brasileiros: resultados não-esperados dos avanços da seguridade rural. Textos para Discussão №1066, Rio de Janeiro, IPEA, 2005. Disponivelem : http://repositorio.ipea.gov.br/handle/11058/1925. Acesso em : 15 de julho de 2008.

FAGNANI, Eduardo. A. Ajuste econômico e financiamento da política social brasileira: notas sobre o período 1993/1998. Economia e Sociedade, Campinas, v.13, n. 2, 1999.

HENRIQUES, Wilnes. O capitalismo selvagem: um estudo sobre a desigualdade no Brasil. 1999. Tese (Doutorado em Economia),Universidade Estadual de Campinas, UNICAMP, Campinas, 1999.

HOFFMANN, Rodolfo.; KAGEYAMA, Ângela. Pobreza, insegurança alimentar e pluriatividade no Brasil. Revista Teoria e Evidência Econômica, Rio Grande do Sul, v. 14, n. 29, p. 9-35, jul/dez de 2007.

LAVINAS, Lena . O Barato da Pobreza. Inteligência, Rio de Janeiro, v. III, p. 40-46, 1998.

MARIANO, S. A; CARLOTO, C. M. Gênero e combate à pobreza: programa Bolsa Família.Rev. Estud. Fem. Florianópolis, v.17 n.3, sept./dec. 2009.

MATTEI, Lauro. Redução da pobreza na América Latina num contexto de crise econômica mundial. In: MODENESI, André, et al. (Org.). Sistema financeiro e política econômica em uma era de instabilidade: tendências mundiais e perspectivas para a economia brasileira. 1.ed. Campus/Elsevier - Rio de Janeiro - RJ 2012.

MATTEI, Lauro. Pobreza e Política de Desenvolvimento Territorial: noções, metodologias de mensuração e estratégias de enfrentamento do problema. In: MIRANDA, Carlos; TIBURCIO, Breno. (Orgs. da Série); Leite, Sérgio (Org. dos Textos). Políticas de Desenvolvimento Territorial e Enfrentamento da Pobreza Rural no Brasil. Série Desenvolvimento Sustentável, v.19. Brasília: IICA, agosto de 2013. p. 89-103. 
REGO, Walquiria; e PINZANI, Alessandro. Vozes do Bolsa Família: autonomia, dinheiro e cidadania. Editora da Unesp, São Paulo, 2013.

ROCHA Sonia. Opções metodológicas para a estimação de linhas de indigência e pobreza no Brasil. Textos para discussão №0720. Brasília, IPEA, 2000. 